ridge, and dressing-forceps were introduced into the wound and a little pus, mixed with blood and serum, escaped. A small drainage tube was introduced into the centre of the wound, the rest of which was sutured. On the following day, June 27, the oedema of the lower lid and corresponding side of the face was more marked. Some pus was stated to have escaped by the drainage tube, the mouth of which also contained similar fluid. Mr. Percy $\mathrm{H}$. Dean, who was called in consultation, deepened the original incision and found pus, not in great quantity, at the upper and inner part of the orbit. He next incised the lewer lid, at the inner end of which he also found and evacuated pus. The bone in the last-named position was bare. A drainage tube, was inserted through the lower wound, and a piece of gauze was left in the upper wound. Finally, the wounds were closed with sutures.

I did not have the opportunity of seeing the patient again, but I learned from Dr. Macdonald Brown that recovery was complete.

\title{
Conclusions
}

1. In young subjects, usually under five years of age, a form of orbital inflammation or suppuration is not infrequent.

2. The condition is always unilateral.

3. There are clinical grounds for believing that an acute inflammation of the anterior ethmoidal cells is the primary condition.

4. The prognosis is good, since the condition undergoes resolution often without surgical intervention.

\section{A CASE OF HYALINE BODIES ON THE OPTIC DISC}

\author{
BY \\ G. VineR, Capt. R.A.M.C.
}

(With plate.)

No. 34844 Gnr. W-, Australian Field Artillery, aged 38, admitted to Ophthalmic Department, No. 3 General Hospital, France, November 14, 1917, with a diagnosis of shell wound of left eye.

On examination, there was a contused wound with much ecchymosis, situated on the left upper lid and eyebrow, close to the outer canthus; no foreign body present in wound and no fracture detected. Left globe intact, and all external appearances normal. L.V. $=6 / 24$ c. +1.00 D. cyl. axis vert. $=6 / 12$. Field of vision full except in lower and nasal quadrant, where it is contracted to $45^{\circ}$. No central scotoma, but the blind spot appears to be distinctly larger than normal. 


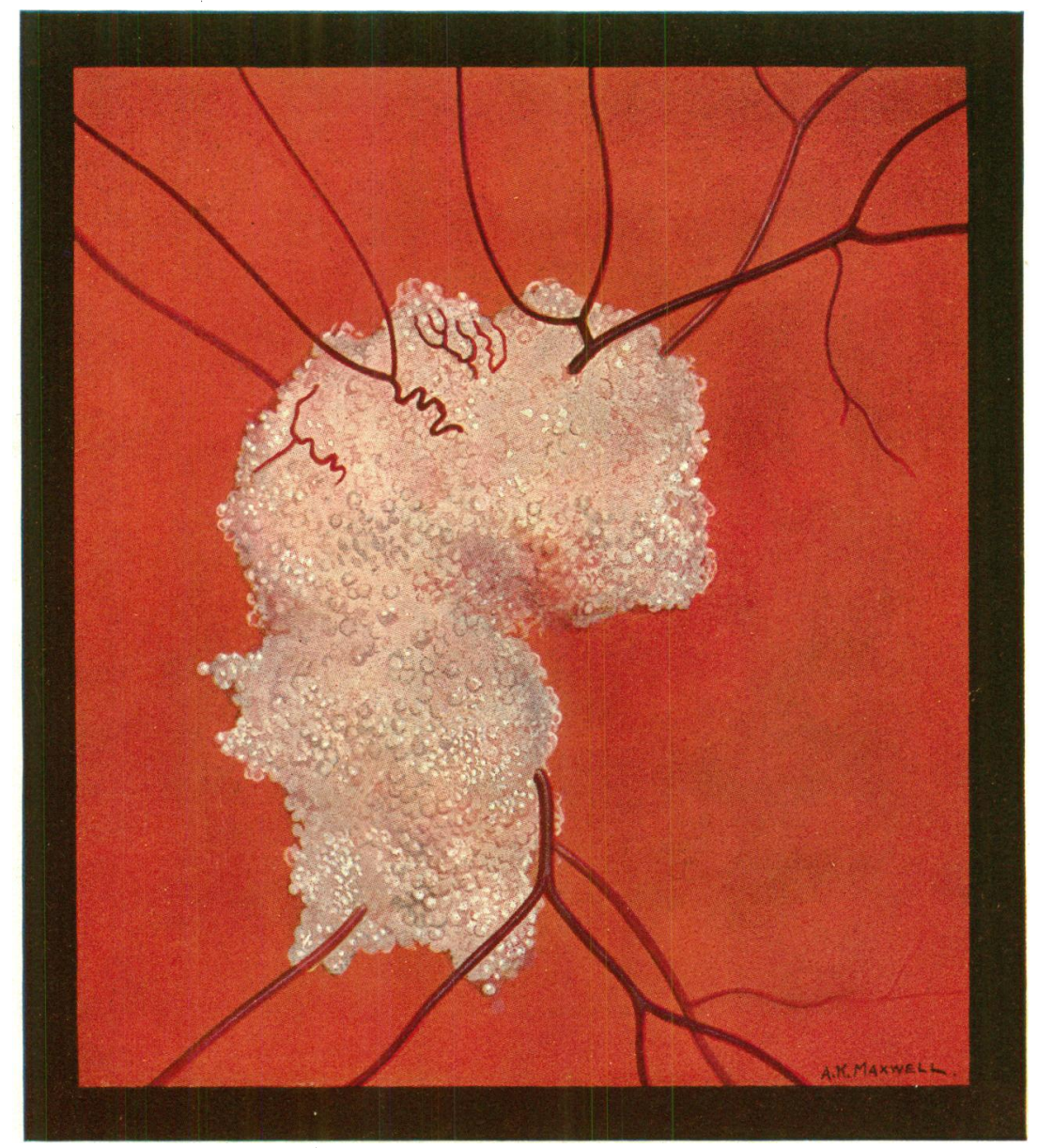

To illustrate CAPTAIN Viner's CONTRIBUtion ON "A Case of Hyaline Bodies on the Optic Disc." 
Ophthalmoscope: The media are clear except in extreme upper temporal periphery, where there are several large vitreous haemorrhages which partially obscure an extensive concentric rupture of the choroid in this region. No part of the optic disc is visible : it is completely hidden by a lobulated mass, irregular in outline, semi-translucent and gelatinous in appearance, bluish white in colour. The mass consists of innumerable but discrete round hyaline bodies lying in front of the disc and retinal vessels; the latter are for the main part buried in the mass, emerging near its edge, and are, with two exceptions, healthy in appearance. Near the upper edge there are two small and very tortuous dilated veins coursing over the upper quarter of its surface. Two small arterial branches running from beneath the mass towards the macula present the signs of perivasculitis. There are no newly formed vessels present, and no other signs of any previous inflammatory changes in the eye. The highest plus lens which focusses the surface of the mass is $3 \mathrm{D}$.

I am indebted to Sergt. Maxwell, R.A.M.C., for the excellent painting of the fundus seen by the direct method.

\section{A REVERSIBLE SCREEN STEREOSCOPE *}

\section{BY \\ A. C. Hudson, LONDON.}

THIS instrument is a modification of one first described several years ago (Ophthal. Rev., December, 1912), and exhibited at the meeting of the Ophthalmological Society of the United Kingdon in 1914.

The eye pieces consist of plane-prisms (in place of the original sphero-prisms), each of which is of $4^{\circ}$ angle of deviation, and is mounted at the extremity of a bar bearing at its other extremity a cell to hold a diagram or picture. The bars cross one another obliquely, the degree of obliquity of the angle of crossing being determined at any moment by the position of a vertical pin which can be moved freely in an antero-posterior direction within a slot which traverses each bar longitudinally. This pin supports the screen, which, by means of a hinge mechanism, can be converted from a central narrow screen to two screens with a central aperture, and vice versâ. When the screen is disposed in the first-mentioned position, and the prisms are arranged base outwards (Fig. 1), the picture in the right-hand cell is visible to, and that in the left-hand cell screened from, the right eye, while the left eye can see only the

\footnotetext{
* Shown at the meeting of the Ophthalmological Society U.K., April, 1918.
} 